\title{
Assessment of Factors Influencing the Development and Sustainability of Small Scale Foundry Enterprises in Nigeria: A Case Study of Lagos State
}

\author{
Kehinde A. Olanipekun
}

Centre for Entrepreneurship and Innovation, University of Ibadan, Ibadan, Nigeria. Email:kennyolanipekun@gmail.comTel:+2348037181083

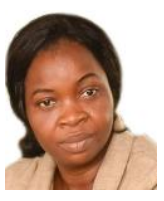

\begin{abstract}
The study identifies types of small scale foundry enterprises operating in Lagos State and also assesses their development and sustainability. Data for the study were obtained from thirty (30) selected small scale foundry enterprises in Lagos and randomly sampled one hundred and fifty (150) of their consumers using questionnaire, focus group discussion (FGD) and Key informant Interview (KII). Data was analyzed using simple frequency method, statistical package of social sciences (SPSS) and qualitative analysis from the FGD and KII. The study revealed that the majority of the foundry enterprises jobbing foundries. The management strategy of the enterprises in terms of reliability (2.11), product and service quality (2.29), and business relationship with consumers (2.09) were satisfactory. Overall ranking shows erratic power supply, flooding market with imported goods, difficulty in obtaining raw materials, flooding the market with imported goods, low linkage between the knowledge institution and the industry, policy discontinuity as factors that highly affect the development of the foundry enterprises. It was concluded that most foundries in Lagos State in Nigeria are jobbing foundries and the remaining few are production foundries. Also, the rate of development of the foundry sector in Nigeria is very low. It was recommended that government policy continuity, provision of soft loan to foundry entrepreneurs, stable power supply, availability of raw materials at low cost, improving the linkage between the knowledge institution and the industry would enhance the development and sustainability of the small scale foundry enterprises in Nigeria.
\end{abstract}

Keywords: Foundry, Small-Scale enterprise, Development, Sustainability, Knowledge institution, Linkage, policy discontinuity. JEL Classification: L1, L6, M10, M11, OO, O2, O5.

Citation | Kehinde A. Olanipekun (2020). Assessment of Factors Influencing the Development and Sustainability of Small Scale Foundry Enterprises in Nigeria: A Case Study of Lagos State. Asian Journal of Social Sciences and Management Studies, $7(4): 288-294$. History:

History:

Received: 21 September 2020

Revised: 13 October 2020

Accepted: 29 October 2020

Published: 16 November 2020

Licensed: This work is licensed under a Creative Commons

Attribution 3.0 License $(\mathrm{cc})$ (ir

Publisher: Asian Online Journal Publishing Group
Funding: This study received no specific financial support.

Competing Interests: The author declares that there are no conflicts of interests regarding the publication of this paper.

Transparency: The author confirms that the manuscript is an honest, accurate, and transparent account of the study was reported; that no vital features of the study have been omitted; and that any discrepancies from the features of the study have been omitted
study as planned have been explained.

study as planned have been explained.
Ethical: This study follows all ethical practices during writing.

\section{Contents}

1. Introduction

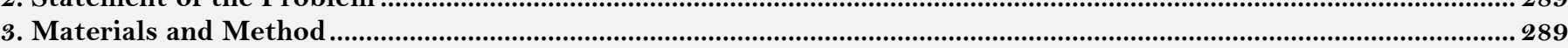

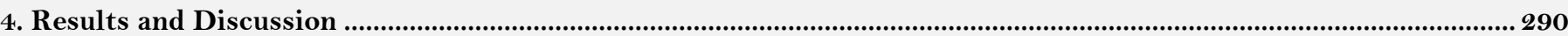

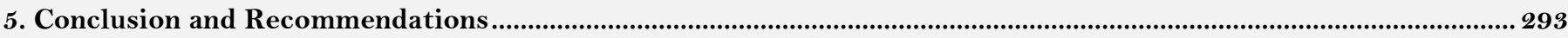

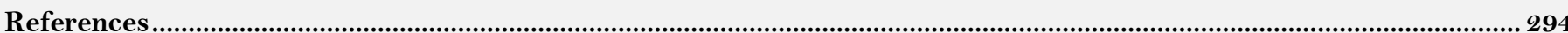




\section{Contribution of this paper to the literature}

This paper gave more insight to the challenges facing the small scale foundry enterprises in Nigeria with focus on Lagos State. It also made recommendations emanating from the study that could bring about sustainable development and growth to the foundry enterprise in Nigeria.

\section{Introduction}

The importance of the small-scale sector cannot be underestimated in any economy given the fact that it occupies a position of prominence and contributes over $50 \%$ of the industrial production in terms of value addition. The SMEs accounts for one-third experts in the manufacturing sector and employs the largest manpower or labor next to agriculture. Casting in the foundry industry involves the manufacture of metal products in a single step from liquid to solid without intermediate operation of mechanical workings such as rolling, fabrication or forging. One of the oldest metal processes is casting to desired shape of the consumer. It involves pouring out of molten metal into a prepared mold cavity of the desired shape and allowing the molten metal to solidify. It dates approximately to four thousand (4000) B.C." (Khanna, 1997). A wide variety of size and shapes of intricate nature can be produced in different metals. Foundry processes can be divided into two parts based on the materials being cast, that is, whether it is ferrous or non-ferrous foundries. "it could also be classified based on products, quantity and organizational framework" (lbhabode, 1997).

The advantages of metal casting over other manufacturing:

Casting provides the greatest freedom of design in terms of shape, size and product quality. It impacts uniform directional properties and better vibration damping capacity to the cast part. Shapes difficult and uneconomical to produce through other manufacturing processes could be achieved at low cost through casting processes. Metal casting enables product to be cast in one piece, thereby eliminating the need of metal joining processes. Very heavy and bulky parts (like those of power plants and mill housing), that are sometimes difficult to fabricate may be cast with ease. Metals difficult to be shaped by other manufacturing processes may be cast with little or no difficulty. Casting can be designed for equal distribution of loads (on all members of a product) and for minimum stress concentration in order to achieve more strength and increase service life. Casting processes can classify into four groups: cottage, small, medium large scale enterprise. The small scale foundry enterprise consists of individual entrepreneur who are self-employed and have some skilled labor and also apprentices to make the job smooth and faster. In order to aid achieving sustainable development and growth in the metal casting industry, it is pertinent to assess the performance of the foundry enterprises in the economy, identify the factors militating against its growth and possible ways to minimize them, identify the efforts being made by the industry to improve its growth and possible assistance from the government in developing the sector.

Majority of the foundries in Nigeria are small scale, many of which are mainly small job outfit, to compliment other sector like their machine and metal fabrication shops. "their products ranges from industrial spare parts like brake shoe for rolling stock, pulleys, gears, shafts and brass bushing” (Adejuyigbe, 1979; Ibitoye, 1995). The capacity of the country's foundry industry is put at 152,000 metric tones annually which is made up of about $59.1 \%$ (60,178 metric tones) cast iron, $27.3 \%$ (41,465 metric tones) of cast steel and $33.1 \%$ (51,370 metric tones) nonferrous all valued at about 19.6 billion naira (US $\$ 196.3$ million). "this output from a total of about 60 active foundries is considered unimpressive with the well over 7,000 active foundry shops, with an annual output of about 3million metric tones per annum in India”.

Raw Material Research and Development Council (1991) also reported about the difficulty faced in obtaining metal scraps locally and this scarcity had led to a large increment in the price of the scraps. According to a report of the RMRDC in 1991, there were about 50 foundries, which produce an estimated 80,000 tones of castings annually. Their product ranges include municipal castings, water pipe fittings, grinding media, components for cement industries, automotive castings, agricultural castings and industrial spares. From their survey, this sub sector has remained largely undeveloped despite the high demand for foundry products. Enhanced use of the existing foundries is handicapped occasionally by the prevailing dull economic activities, low capacity utilization of installed facilities and in some cases outright inactivity.

The total installed capacity of about 30 foundries that were surveyed by the RMRDC was about 50,000 tones. Their current capacity utilization as at 1996 was $30-40 \%, 12-20 \%$ and $60-70 \%$ for private organized foundries, public sector capacity foundries and small-scale foundries respectively.

\section{Statement of the Problem}

Foundry industry can be a hub for economic development in any nation. This is because a considerable number of the foundry products serve as equipment or replacement materials for all other industries such as agriculture, transportation, petrochemical, cement and quarrying (Atanda \& Ibitoye, 2004). The level of awareness on its role on the economic development in Nigeria is low.

In the Asian countries small scale foundries add a lot to the GDP of the economy while Nigeria, the contribution of the small scale foundry enterprise is almost insignificant. This can be attributed to the flooding of the market with imported goods which made patronage of the locally produced foundry products very low. This has led to some of the foundry firms folding up thereby leading to a decrease in their number. Since it is a multi chain reaction, it has also led to high increase in unemployment rate for those already trained to work in the enterprise. Since the foundry industry is of great importance to achieving sustainable economic development of the nation, hence, the need to assess the factors influencing the development and sustainability of the foundry enterprises in Nigeria.

\section{Materials and Method}

The study was carried out mainly in Lagos State. This was because small scale foundry enterprises are more prominent in the state and its suburb than any other state in Nigeria. The study adapted mixed method approach using both quantitative and qualitative methods. Structured and unstructured questionnaires and multiple visit 
approach were used to collect the information needed. Focus group discussion (FGD) and key informant interview (KII) was also used in the study. Participants in the focused group were the small scale foundry entrepreneurs. Participants for the KII include respondents from knowledge based institutions and consumers of the foundry products.

Purposive sample size of 30 respondents was used for the survey whose list was gotten from the record of Foundry Association of Nigeria, Lagos branch and randomly sampled one hundred and fifty (150) of their consumers within and outside the state. A pre-test was carried out in 5 foundry firms in Oyo State to determine the validity and reliability of the questionnaire.

Both descriptive and inferential statistics were employed in the analysis of the survey data. The quantitative data that may have influence on the development and sustainability of the foundry enterprises were analyzed using Statistical Package of Social Science (SPSS). This was presented simple frequency, percentage and relative importance index (RII). Qualitative instruments in form of focus group discussion (FGD) in- depth interview (IDI) were used to obtain information from the participants. This was recorded with audio tape, transcribed and translated.

\section{Results and Discussion}

The survival of the foundry enterprises depends mainly on the percentage of the small and medium scale enterprises. Ninety percent $(90 \%)$ of the foundry enterprises produces for small organizations, eighty six percent $(86 \%)$ produces for medium organizations and forty seven percent $(47 \%)$ for large organizations. Also, all of the enterprises accept jobs from individuals that come to their establishments for any type of foundry work. This implies that majority of the foundry enterprises are jobbing foundries. This corroborate the work of Andrews and Gikunoo (2011) which states that the small scale foundries in Ghana are semi production foundries and have contributed greatly to the growth of the national economy.

Most of the foundry enterprises (83\%) produce many products while few (10\%) produces single products Table 1. Some of these establishments consume some of their products themselves as confirmed by the respondents. For instance the rotary furnace that is usually used for melting scraps and metals are produced by the foundry enterprise themselves. Majority of the foundry enterprise (93\%) also produce for individual consumption while some of the products are consumed by other organizations (90\%). This also indicates that most of the foundries are jobbing foundries. It was observed that in the operations management of the foundry enterprises, about eighty eight percent $(88 \%)$ of the entrepreneur of the foundry establishments indicated that there had been product and process innovations within the past five to ten years. The innovations range from the use of pit furnace to crucibles and later on to rotary furnace. Sixty two percent $(62 \%)$ claimed that everybody is involved in ensuring the quality management while seven percent $(7 \%)$ indicating that specific individual was charged with ensuring the quality of their products.

\begin{tabular}{l|c} 
Table-1. Production activities of the Foundry Firms in Lagos State $(\mathrm{n}=30)^{*}$ \\
\hline Parameters & $\mathbf{\%}$ \\
\hline Production for large-scale organizations & 46.68 \\
\hline Production for medium-scale organization & 86.67 \\
\hline Production for small-scale organization & 83.33 \\
\hline Production for individuals & 93.33 \\
\hline Organization produces: & 10 \\
\hline Single products & 83.33 \\
\hline Many products & 6.67 \\
\hline Other types of productions & 73.33 \\
\hline Consumption of the products by: Individual & 93.33 \\
\hline Other organizations The organization & 90.00 \\
\hline Note: *Multiple responses. &
\end{tabular}

Some of the entrepreneurs rated their product as excellent forty one percent (41\%) of the consumers are very satisfied with the product quality while forty seven percent $(47 \%)$ are satisfied Table 2 . This shows that the local products produced by the local foundry entrepreneurs meet the needs of the people (Andrews \& Gikunoo, 2011). Therefore utilization of local products should be encouraged so as to develop this sector. This can be achieved by banning of imported products and increasing tariff rate on imported products. Also, organizing trade fair for exhibition of locally made foundry products will increase the patronage. Majority of the enterprises, seventy eight percent $(78 \%)$, obtain their raw materials both locally and by importation, while the rest used only local materials throughout their production processes. This shows bulk of the raw materials used in the foundry are locally sourced. Some of the difficulties being encountered in obtaining the raw materials in the foundry enterprises were of cost, transportation and their availability to foundry entrepreneurs as reported by eighty five percent $(85 \%)$ of the entrepreneurs. High price of fuel is also one of the factors adding to the difficulties being faced by the entrepreneurs. Also, some of the facilities or equipment used during the production was obtained locally and through importation sixty seven $(67 \%)$. Twenty six percent $(26 \%)$ of the foundry industry used only local facilities alone.

Forty three percent (43\%) experienced breakdown on a yearly basis, sixteen percent $(16 \%)$ every six months, seven percent $(7 \%)$ quarterly and three percent (3\%) bimonthly. About thirty percent $(30 \%)$ of the entrepreneurs claimed that breakdown of equipment could occur at any period and the time taken to repair each part varied depending on the gravity of the repair work to be done to the equipment to function properly. Forty percent (40\%) of the foundry enterprises changed their equipment within two years while twenty percent (20\%) changed theirs after five years. The production system is very economical to thirteen percent (13\%) and economical to about fifty seven percent $(57 \%)$ of the entrepreneurs while thirty five percent $(35 \%)$ claimed that it was not economical. On average, it can be said that the source of energy. The issue of electrical power is central to the economic viability of the foundry enterprises. 
Table-2. Production management of the foundry enterprises $(\mathrm{n}=30)^{*}$

\begin{tabular}{|c|c|c|}
\hline Parameters & Frequency & $\%$ \\
\hline \multicolumn{3}{|c|}{ Innovations within the Organization } \\
\hline Yes & 25 & 83.33 \\
\hline \multicolumn{3}{|l|}{ Product rating } \\
\hline Excellent & 12 & 40.00 \\
\hline Very good & 14 & 46.67 \\
\hline Fairly good & 4 & 13.33 \\
\hline \multicolumn{3}{|l|}{ Method of quality management } \\
\hline Everybody is involved & 19 & 63.33 \\
\hline A particular unit is involved & 8 & 26.67 \\
\hline An individual is involved & 3 & 10.00 \\
\hline \multicolumn{3}{|l|}{ Source of raw materials } \\
\hline Local & 9 & 30.00 \\
\hline Both & 21 & 70.00 \\
\hline \multicolumn{3}{|c|}{ Difficulties in obtaining raw materials } \\
\hline Yes & 24 & 80.00 \\
\hline \multicolumn{3}{|c|}{ Types of difficulties experienced by the foundry operators } \\
\hline Cost of materials & 11 & 36.67 \\
\hline Transportation & 9 & 30.00 \\
\hline Quantity & 10 & 33.33 \\
\hline \multicolumn{3}{|l|}{ Source of Finance } \\
\hline Personal Savings & 23 & 76.67 \\
\hline Bank Loan & 6 & 22.22 \\
\hline Others & 1 & 3.70 \\
\hline \multicolumn{3}{|c|}{ Turnover of the Foundry Enterprises } \\
\hline Excellent & 7 & 23.33 \\
\hline Very good & 12 & 40.00 \\
\hline Good & 6 & 5 \\
\hline Fair & 5 & 16.67 \\
\hline \multicolumn{3}{|l|}{ Growth } \\
\hline Positive growth & 25 & 83.33 \\
\hline Negative growth & 5 & 16.67 \\
\hline \multicolumn{3}{|l|}{ Product grade } \\
\hline Excellent & 11 & 36.67 \\
\hline Very Good & 15 & 50.00 \\
\hline Good & 4 & 13.33 \\
\hline \multicolumn{3}{|l|}{ Source of facilities } \\
\hline Local & 7 & 23.33 \\
\hline Imported & 2 & 6.67 \\
\hline Both & 21 & 70.00 \\
\hline \multicolumn{3}{|l|}{ Equipment maintenance } \\
\hline Within the organization & 6 & 20.00 \\
\hline Outside the organization & 1 & 3.33 \\
\hline Both & 23 & 76.67 \\
\hline
\end{tabular}

Table-2. Production Management of the Foundry Enterprises $(\mathrm{n}=30)^{*}$ cont'd.

\begin{tabular}{|c|c|c|}
\hline Parameters & Frequency & $\%$ \\
\hline \multicolumn{3}{|l|}{ Equipment breakdown } \\
\hline Bimonthly & 1 & 3.33 \\
\hline Quarterly & 2 & 6.67 \\
\hline Every 6 months & 5 & 16.67 \\
\hline Yearly & 13 & 43.33 \\
\hline \multicolumn{3}{|l|}{ Equipment repair } \\
\hline Few hours & 6 & 20.00 \\
\hline Few days & 5 & 16.67 \\
\hline One week & 10 & 33.33 \\
\hline One month & 3 & 10.00 \\
\hline Others & 6 & 20.00 \\
\hline \multicolumn{3}{|l|}{ Equipment replacement } \\
\hline$<1$ year & 4 & 13.33 \\
\hline 1 year & 3 & 10.00 \\
\hline 2 years & 12 & 40.00 \\
\hline 5 years & 6 & 20.00 \\
\hline$>5$ years & 5 & 16.67 \\
\hline \multicolumn{3}{|l|}{ Production Economy } \\
\hline Very economical & 4 & 13.33 \\
\hline Economical & 17 & 56.67 \\
\hline Not economical & 9 & 30.00 \\
\hline \multicolumn{3}{|l|}{ Method of conserving energy } \\
\hline Combine electrical energy with fuel & 26 & 86.67 \\
\hline Use of fuel only & 4 & 13.33 \\
\hline Total & 30 & 100 \\
\hline
\end{tabular}




\subsection{Factors Affecting Production and Performance of the Foundry Industry}

The result of the performance rating of the foundry enterprises by the consumers showed that reliability of the organization and delivery time were rated as average, while rating for the precision of the products was poor. Product service quality was rated above average and business reliability with the consumers and responsiveness were rated just above average (Table 3 ).

The performance of the enterprises in terms of reliability of the organization (2.11), product and service quality (2.29), and business relationship with consumers (2.09), delivery time (2.01) and responsiveness to consumer feedback (2.03) were satisfactory based on 3-point Likert scale Table 3. However factors such as erratic power supply, difficulty in obtaining raw materials, exportation of scraps, flooding market with imported goods, inconsistency in government policies, inadequate or non-existence of funds, and high cost of labour were factors militating against the development and performance of this sector Table 4. Analysis shows that the foundry firms, knowledge institutions and the consumers considered erratic power supply, flooding market with imported foundry products as factors that were highly affecting the performance of the foundry industry This is in agreement with the findings of Nwosu, Ikwu, and Uzorh (2013) that poor electricity supply is one the greatest infrastructure problem confronting the manufacturing sector which imposes a huge cost on the firm arising from idle production workers, spoiled materials, lost output, damaged equipment and restart costs. The consumer and implementing agencies considered obtaining local raw materials as the factor highly affecting performance. Other factors affecting performance are high cost of materials, low patronage of local products and high cost of labor which is similar to the problems facing the foundry industry in China (Tata Energy Research Institute, 1999).

\begin{tabular}{l|c}
\multicolumn{2}{c}{ Table-3. Performance rating of the small scale metal casting industry enterprises. } \\
\hline Parameters & Weighted Mean \\
\hline (i) Reliability of the Organization & 2.11 \\
\hline (ii) Adequacy of Price of Products & 1.73 \\
\hline (iii) Precision of Products & 0.90 \\
\hline (iv) Product and Service Quality & 2.29 \\
\hline (v) Business Relation-ship with consumers & 2.09 \\
\hline (vi) Delivery Time & 2.01 \\
\hline (vii) Responsiveness to Consumer Feedback & 2.03 \\
\hline Note: Sum =6. Mean = 2, Standard Deviation =1, Range = Mean \pm Standard Deviation.
\end{tabular}

Note: Sum $=6$. Mean $=2$, Standard Deviation $=1$, Range $=$ Mean \pm Standard Deviation.

1.0 - Low, 2.0 - Average, 3.0 - High Decision Rule $=2.0$

Table-4. Factors affecting development and sustainability of the small scale foundry enterprise

\begin{tabular}{|c|c|c|c|c|c|c|c|c|c|c|}
\hline \multirow[t]{2}{*}{$\begin{array}{l}\text { Factors affecting production } \\
\text { performance variables }\end{array}$} & \multicolumn{2}{|c|}{$\begin{array}{l}\text { Research } \\
\text { institutes }\end{array}$} & \multicolumn{2}{|c|}{ Consumers } & \multicolumn{2}{|c|}{$\begin{array}{c}\text { Foundry } \\
\text { entrepreneurs } \\
\text { and staff }\end{array}$} & \multicolumn{2}{|c|}{$\begin{array}{l}\text { Implementing } \\
\text { agencies }\end{array}$} & \multicolumn{2}{|c|}{$\begin{array}{l}\text { Overall } \\
\text { ranking }\end{array}$} \\
\hline & 国 & 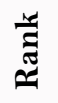 & 春 & 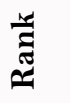 & 国 & జี & 国 & 苟 & 丰 & 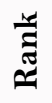 \\
\hline $\begin{array}{l}\text { Flooding market with imported } \\
\text { goods }\end{array}$ & 1.00 & 1 & 0.90 & 3 & 0.93 & 2 & 0.88 & 6 & 0.92 & 2 \\
\hline Erratic power supply & 1.00 & 2 & 0.91 & 2 & 0.93 & 2 & 0.75 & 11 & 0.92 & 1 \\
\hline Low patronage of local products & 0.95 & 3 & 0.86 & 6 & 0.85 & 5 & 0.91 & 3 & 0.87 & 5 \\
\hline Inadequate man power & 0.93 & 4 & 0.79 & 8 & 0.79 & 6 & 0.75 & 11 & 0.80 & 8 \\
\hline $\begin{array}{ll}\text { Inexperienced } & \text { labor/human } \\
\text { resources } & \end{array}$ & 0.92 & 5 & 0.76 & 11 & 0.75 & 10 & 0.72 & 16 & 0.78 & 10 \\
\hline High exchange rate & 0.91 & 6 & 0.64 & 15 & 0.63 & 15 & 0.88 & 6 & 0.68 & 15 \\
\hline High import duty & 0.91 & 6 & 0.62 & 16 & 0.60 & 17 & 0.81 & 8 & 0.66 & 16 \\
\hline Other source of power & 0.89 & 8 & 0.81 & 7 & 0.78 & 7 & 0.75 & 11 & 0.81 & 7 \\
\hline High cost of materials & 0.89 & 8 & 0.89 & 4 & 0.94 & 1 & 0.91 & 3 & 0.90 & 4 \\
\hline Usage of obsolete equipment & 0.88 & 10 & 0.76 & 12 & 0.73 & 12 & 0.78 & 9 & 0.77 & 11 \\
\hline Technology transfer & 0.87 & 11 & 0.79 & 8 & 0.78 & 8 & 0.78 & 9 & 0.79 & 9 \\
\hline Lack of innovation & 0.86 & 12 & 0.72 & 14 & 0.73 & 13 & 0.69 & 17 & 0.74 & 14 \\
\hline Obtaining imported materials & 0.86 & 12 & 0.56 & 16 & 0.63 & 16 & 0.75 & 11 & 0.62 & 17 \\
\hline $\begin{array}{l}\text { Inconsistency in Government } \\
\text { Policies }\end{array}$ & 0.86 & 12 & 0.78 & 10 & 0.64 & 14 & 0.91 & 3 & 0.76 & 12 \\
\hline High cost of labor & 0.81 & 15 & 0.88 & 5 & 0.76 & 9 & 0.97 & 1 & 0.85 & 6 \\
\hline Transportation & 0.80 & 16 & 0.75 & 13 & 0.75 & 11 & 0.75 & 11 & 0.75 & 13 \\
\hline Obtaining local raw materials & 0.78 & 17 & 0.95 & 1 & 0.89 & 4 & 0.94 & 2 & 0.92 & 3 \\
\hline
\end{tabular}

However studies revealed that erratic power supply and flooding market with imported goods are the ones highly affecting development and growth of the foundry enterprise. Manufacturers' Association of Nigeria (M.A.N) reported the result of a survey carried out by the United Nations Industrial Development Organization UNIDO in 2008 on the factors affecting the growth rate of the manufacturing industry. The result showed that lack of infrastructure, lack of access to funds and low demand for product are major factors affecting growth rate. This support the findings of Onuoha (2005) in a survey carried out on the manufacturing firms in Abia State in 2005 that the manufacturing sector's environment in Nigeria is problematic and harsh. Apata and Alani (2016) also reported that source of financing small scale foundry enterprises is one of major challenge the sector is facing. The findings also showed that these problems can lead to business failure which essentially is seen as rising operational costs without increasing sales volume. Some of these factors according to respondents during interview have led to some foundries folding up totally or operating at skeletal levels and equipment are grounded and depreciating in value. Similar challenges are also facing the foundry industry in Ghana and this has resulted into production of low 
quality cast products compared to imported ones. In addition, lack of proper quality control management practices resulted into lots of reworks during the manufacturing processes of the various components (Andrews \& Gikunoo, 2011). Respondents of the study urged the federal government to find lasting solution to the problem of instability of power and flooding market with imported goods coupled with exportation of scraps which can serve as input for the foundry industry in Lagos State.

\subsection{Adequacy of Factors That Can Sustain the Foundry Enterprise}

Table 5 showed various factors that were listed to all the respondents to determine which one is most adequate in sustaining the foundry industry. Result showed that mean rating ranges from 2.55 to 3.88. Enforcement of local utilization of local foundry products in all government contracts (mean=3.88) was rated by the foundry firms as well as maintaining national industrial policy as related to the metal sector $($ mean $=3.88$ ) by the implementing agencies as the most adequate way of sustaining the foundry industry.

Table-5. Adequacy of factors in sustaining the foundry enterprise.

\begin{tabular}{|c|c|c|c|c|}
\hline Parameters & $\begin{array}{l}\text { Mean } \\
\text { K.I }\end{array}$ & I.A & F.F & Consumers \\
\hline Provision of adequate foundry raw materials & 3.44 & 3.00 & 3.57 & 3.36 \\
\hline Provision of good infrastructure & 3.44 & 3.38 & 3.61 & 3.45 \\
\hline Provision of R and D control laboratory to ensure good quality & 3.40 & 3.08 & 3.59 & 3.24 \\
\hline $\begin{array}{l}\text { Enforcement of local utilization of local foundry products in all } \\
\text { government contracts }\end{array}$ & 3.40 & 3.25 & 3.88 & 3.33 \\
\hline Encourage metal scrap recycling & 3.40 & 3.25 & 3.65 & 3.62 \\
\hline $\begin{array}{l}\text { Interaction of the government agency with foundry industry to obtain } \\
\text { specification of all their materials }\end{array}$ & 3.28 & 2.88 & 3.45 & 3.13 \\
\hline $\begin{array}{l}\text { Manual production on safety regulation to minimize accident and } \\
\text { hazard }\end{array}$ & 3.20 & 3.00 & 3.04 & 3.08 \\
\hline Maintaining national industrial policy as relate to the metal sector & 3.20 & 3.88 & 3.28 & 3.16 \\
\hline Using local foundry products in other manufacturing industries & 3.08 & 3.00 & 3.70 & 3.40 \\
\hline $\begin{array}{l}\text { Availability of fiscal and monetary policy to support the industry } \\
\text { exportation of foundry products }\end{array}$ & 3.08 & 2.55 & 3.48 & 3.08 \\
\hline $\begin{array}{l}\text { Maintaining good health and environment standard goo funding of R } \\
\text { and D }\end{array}$ & 3.20 & 3.00 & 3.22 & 3.16 \\
\hline Establishment of metal data bank & 3.04 & 2.75 & 2.96 & 2.88 \\
\hline Compliance with international standard (SON,ISO) & 3.04 & 2.75 & 3.28 & 3.25 \\
\hline $\begin{array}{l}\text { Removing non -tariff barriers that disrupts industry access to } \\
\text { international market }\end{array}$ & 3.00 & 3.57 & 3.57 & 2.82 \\
\hline Tariff regulation on foundry industry & 2.92 & 3.13 & 3.13 & 2.87 \\
\hline
\end{tabular}

Key: K.I= Knowledge Institutions, I.A=Policy Implementing Agencies, F.F = Foundry Firms.

Very Adequate $=4$, Adequate $=3$, Not Adequate $=2$, Not sure $=1$ Decision Rule $=3.0$

This is followed by encouraging metal scrap recycling (mean=3.65) by the foundry firms. Recycling these metals will lead to reduction in unit cost per production and it will also reduce waste of materials. This corroborate a report in a survey by Archarya, Archarya, and Vadher (2014) which states that recycling old iron castings was the easiest manner to remake another casting and reuse society's unwanted cast articles. Other factors with mean above 3.0 include provision of good infrastructure which will also lead to improving and development of the sustainability of the foundry industry (3.61), provision of adequate raw materials and using local foundry products in other manufacturing industries (3.59), and provision of research and development control laboratory to ensure good quality (3.70).

\section{Conclusion and Recommendations}

The development and sustainability of the foundry enterprise is considered average due to some factors which include among others inaccessibility of most entrepreneurs to low interest rate loan, erratic power supply, the use of locally fabricated low-tech equipment, non-linkage between the industry and knowledge institutions, flooding market with imported goods and inconsistency in government policies.

The bulk of the raw materials and facilities used in the foundry are locally sourced but on the high side in terms of cost. The products produced by the local foundry entrepreneurs on the average meet the needs of the consumers. The difficulties encountered in the foundry enterprises include difficulty in obtaining raw materials and its high cost, transportation and availability to foundry entrepreneurs, erratic power supply, low patronage, flooding market with imported goods, discontinuity in government policy. It was also inferred that in spite of various challenges encountered, the production system employed in most foundry enterprises is generally economical.

The study recommended that easy access to loans at low interest rate should be made available to the foundry entrepreneurs to assist the existing entrepreneurs to improve and maintain a good product standard through financial institutions like microfinance banks, bank of the industry (BOI). Funds should also be made available as part of initial capital investment to sponsor individual to establish new foundries. However, the existing and new establishment should strive to break-even so as to reduce dependence on government assistance. This can be achieved by employing relevant and competent hands, improving the skill of their employee among others. Linkages between research institutions and the industry should be encouraged by creating a research and development unit $(\mathrm{R} \& \mathrm{D})$. Alternative source of electricity can also be considered and produced at lower rate such as solar power since Nigeria is located in an environment where we have adequate sunlight throughout the year. 


\section{References}

Adejuyigbe, A. (1979). Manufacturing, In Oloku, F.A. et al, eds., "Structure of the Nigeria economy. London: Macmillan.

Andrews, A., \& Gikunoo, E. (2011). Small scale foundries in Ghana: The challenges. Leonardo Electronic Journal of Practices and Technologies, $19(7), 1-12$.

Apata, A. O., \& Alani, G. (2016). Sources of financing small scale foundry enterprise. Journal of Emerging Trends in Engineering and Applied Science, 7(3), 91-94.

Archarya, S. G., Archarya, G. D., \& Vadher, J. A. (2014). A review on evaluating green manufacturing for sustainable development in foundry industry. International Journal of Emerging Technology and Advanced Engineering, 4(1), $232-237$.

Atanda, P. O., \& Ibitoye, S. A. (2004). An appraisal of the foundry industry in Nigeria, a way forward. Paper presented at the Proceedings of The Nigerian Materials Congress (NIMACON), EMDI, Akure.

Ibitoye, S. A. (1995). Unpublished M.Phil Thesis, Department of Metallurgical and Materials Engineering, Obafemi Awolowo University, Ile- Ife, Osun State, Nigeria.

Khanna, O. P. (1997). A textbook of foundry technology (Vol. 2). Danyagani, New Delhi: Dhanpat Ra Publications (P) Ltd.

lbhabode, A. O. (1997). Introduction to manufacturing technology (pp. $217-219)$. Benin-City: Ambik Publishers.

Nwosu, M. C., Ikwu, G. O. R., \& Uzorh, A. C. (2013). Investigation of some factors affecting manufacturing worker's performance in industries in Anambra State of Nigeria. European Journal of Business and Innovation Research, 1(1), 44-71.

Onuoha, B. C. (2005). Impact of government policies on entrepreneurship development (1980-2000); A Study of Abia State, Nigeria. Unpublished Ph.D Thesis, Department of Management Studies, Abia State University, Nigeria.

Raw Material Research and Development Council. (1991). Report on the techno-economic and development council. Survey of the Motor vehicles and Miscellaneous Part Manufacture, 24-25.

Tata Energy Research Institute. (1999). Need for a small-scale perspective. Retrieved from: www.teri.res.in/terin/news/terivision/issue26/tech.htm. 